\title{
Underweight among rural Indian adults: burden, and predictors of incidence and recovery
}

Rajesh Kumar Rai ${ }^{1, *}$, Wafaie Wahib Fawzi ${ }^{2,3,4}$, Sabri Bromage ${ }^{4}$, Anamitra Barik ${ }^{1,5}$ and Abhiijit Chowdhury ${ }^{1,6}$

${ }^{1}$ Society for Health and Demographic Surveillance, Suri 731 101, West Bengal, India: ${ }^{2}$ Department of Global Health and Population, Harvard T.H. Chan School of Public Health, Boston, MA, USA: ${ }^{3}$ Department of Epidemiology, Harvard T.H. Chan School of Public Health, Boston, MA, USA: ${ }^{4}$ Department of Nutrition, Harvard T.H. Chan School of Public Health, Boston, MA, USA: ${ }^{5}$ Suri District Hospital \& Niramoy TB Sanatorium, Suri, West Bengal, India: ${ }^{6}$ Department of Hepatology, School of Digestive and Liver Diseases, Institute of Post Graduate Medical Education \& Research, Kolkata, West Bengal, India

Submitted 20 November 2016: Final revision received 5 September 2017: Accepted 11 September 2017: First published online 10 November 2017

\begin{abstract}
Objective: To study the magnitude and predictors of underweight, incident underweight and recovery from underweight among rural Indian adults.

Design: Prospective cohort study. Each participant's BMI was measured in 2008 and 2012 and categorized as underweight $\left(\mathrm{BMI}<18.5 \mathrm{~kg} / \mathrm{m}^{2}\right)$, normal $(\mathrm{BMI}=$ $18.5-22.9 \mathrm{~kg} / \mathrm{m}^{2}$ ) or overweight/obese $\left(\mathrm{BMI} \geq 23.0 \mathrm{~kg} / \mathrm{m}^{2}\right)$. Incident underweight was defined as a transition from normal weight or overweight/obese in 2008 to underweight in 2012, and recovery from underweight as a transition from underweight in 2008 to normal weight in 2012. Bivariate and multivariable logistic regression analyses were employed.

Setting: The Birbhum Health and Demographic Surveillance System, West Bengal, India.

Subjects: Predominantly rural individuals ( $n$ 6732) aged $\geq 18$ years enrolled in 2008 were followed up in 2012.

Results: In 2008, the prevalence of underweight was 46.5\%. From 2008 to 2012, $25.8 \%$ of underweight persons transitioned to normal BMI, $12.9 \%$ of normalweight persons became underweight and $0 \cdot 1 \%$ of overweight/obese persons became underweight. Multivariable models reveal that people aged 25-49 years, educated and wealthier people, and non-smokers had lower odds of underweight in 2008 and lower odds of incident underweight. Odds of recovery from underweight were lower among people aged $\geq 36$ years and higher among educated (Grade 6 or higher) individuals.

Conclusions: The current study highlights a high incidence of underweight and important risk factors and modifiable predictors of underweight in rural India, which may inform the design of local nutrition interventions.
\end{abstract}

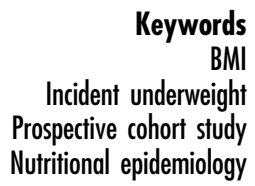

Nutrition transition in developing countries is of considerable interest to international public health researchers and programme and policy makers. India is no exception, where despite an unacceptably high rate of underweight, rapid urbanization and a growing sedentary population have led to rising levels of overweight and obesity ${ }^{(1)}$. Although overweight and obesity remain a growing concern, addressing underweight is still an unfinished agenda in India ${ }^{(2-4)}$, especially in rural settings; this poses a grave challenge to India's public health-care system ${ }^{(5)}$. Undernutrition increases one's susceptibility to infections, related morbidity, disability and mortality, leading to decreased national productivity and economic growth ${ }^{(6-8)}$. An undernourished woman with short stature, iron or protein deficiency, or other nutrient deficiencies has a greater risk of adverse pregnancy outcomes such as obstructed labour or postpartum haemorrhage, and of giving birth to a baby with low birth weight and ill health ${ }^{(9)}$. Underweight among men is indicative of poverty, food insecurity and inadequate health care ${ }^{(5,10)}$.

A large body of research has empirically identified predictors of child undernutrition in India, but the dynamics of adult undernutrition are poorly understood. The determinants of undernutrition are widely studied in 
the global health literature. A framework developed by UNICEF describes poverty as the central underlying cause of undernutrition ${ }^{(11)}$. Many studies have shown socioeconomic, demographic, physiological and behavioural factors associated with undernutrition in India ${ }^{(12-15)}$. However, these studies were conducted using crosssectional survey data, which limits confidence in causal relationships; cross-sectional studies also preclude the ability to discern temporal relationships. Although one recent longitudinal study was conducted among Indian children $^{(16)}$, to our knowledge no longitudinal study on adult undernutrition has recently been conducted in India, especially in rural India where existing social welfare programmes to improve nutritional status have been generally ineffective ${ }^{(17)}$.

Given these knowledge gaps, the present study used prospective cohort data (a baseline survey in 2008 and a follow-up survey in 2012) from a Health and Demographic Surveillance System, located in the Birbhum district of West Bengal, India, to assess the magnitude and predictors of underweight in 2008, and to analyse the predictors of incident underweight and recovery from underweight of 6732 individuals aged $\geq 18$ years.

\section{Methods}

\section{Study setting and data}

The data used in the present study were drawn from a prospective cohort study conducted by the Society for Health and Demographic Surveillance (SHDS). SHDS is a Health and Demographic Surveillance System (HDSS) located in the Birbhum district of the state of West Bengal, India. The Birbhum Health and Demographic Surveillance System (BHDSS) consists predominantly of a rural population spread over four administrative blocks (Mohammad Bazar, Rajnagar, Sainthia and Suri I) and the project office of BHDSS is based in Suri I. At its inception in 2008, a sampling frame of the 2001 census was used to draw stratified self-weighted samples (where each household in a given sampling frame had the same chance of being selected as any other household) of 12300 households and 54585 individuals, applying a probability-proportionalto-size sampling method, with a $10 \%$ expected dropout or non-participation rate ${ }^{(18)}$. Since 2008, BHDSs has gathered information on demographic processes, population health (including nutrition) and health-care utilization in this well-defined cohort. The information on demographic processes including vital events (fertility, mortality and migration) is collected routinely, while focused surveys, mostly longitudinal, are also an important component of BHDSS. The selected sample for BHDSS represents nearly $16 \%$ of the population of Birbhum district and has a response rate of over $98 \%$. More details about the sampling procedure and BHDSS profile are available elsewhere $^{(18)}$.
In 2008, measurement of BMI was taken for the full sample of 29896 individuals aged $\geq 18$ years, while in 2012, BMI measurement was taken for 8177 individuals who participated in blood sample and ultrasonography investigations in the same year. A total of 6732 individuals participated in both rounds of BMI measurement and are included in the current analysis. This analysis excludes women who were pregnant at the time of each survey round as well as women who gave birth during the two months preceding the survey. Data were collected from study participants by forty-four trained surveyors who had at least an undergraduate degree and at least five years of experience with large-scale sample surveys. The surveyors were native speakers of at least one of the local languages - Bengali and Santhali (a tribal language) - and were trained in a rigorous data collection and field monitoring protocol. In case of unavailability of a participant on the survey date, surveyors made every effort (e.g. consulting neighbours or household member, paying multiple visits to the household, and making a prior appointment by telephone) to follow up with the participant to avoid nonresponse and missing data. All data were double-checked for consistency before being determined ready for use ${ }^{(18)}$.

\section{Outcome events}

BMI $\left(\mathrm{kg} / \mathrm{m}^{2}\right)$ is a widely used indicator of adiposity and nutritional status. For Asian populations, the WHO defines a BMI of $<18.5 \mathrm{~kg} / \mathrm{m}^{2}$ as underweight, a BMI of $18.5-22.9 \mathrm{~kg} / \mathrm{m}^{2}$ as normal and a BMI of $\geq 23.0 \mathrm{~kg} / \mathrm{m}^{2}$ as overweight or obese ${ }^{(19)}$. The present study focused on studying underweight: incident underweight was defined as a transition from normal BMI or overweight/obesity in 2008 to underweight in 2012, and recovery from underweight was defined a transition from underweight in 2008 to normal weight in 2012. To calculate BMI, height was measured using a standard anthropometric tape (Bioplus Stature Meter, model number IND/09/2005/815) and a certified electronic weighing scale (model number Omron HN-283) was used to measure weight.

\section{Predictors}

Guided by the existing literature on determinants of BMI, a range of potential predictors were selected for analysis. These included age group (in terms of completed years), sex, marital status, education status (in terms of highest grade of education attained), employment, social group, religion, household wealth quintile, administrative block of residence, current alcohol use, current smoking, current use of smokeless tobacco, availability of health insurance, and record of illness during a period of $30 \mathrm{~d}$ preceding the survey. Information for all predictors was collected in 2008, except for information on illness which was collected in 2012.

The unemployed category of income corresponds to non-household work without pay, permanently disabled persons and full-time students with no source of earnings. 
Primary employment corresponds to individuals who were self-employed, or those who worked in agriculture (as employers), non-agricultural fields (as employers), sharecroppers, agricultural labourers, non-agricultural labourers, income-earning household workers, or other earners of small income. If an individual had an income from a professionally skilled job, business or salary-based service, it was considered secondary or tertiary employment. Social group categories such as Scheduled Castes (SC) and Scheduled Tribes (ST) have been identified by the Government of India as socially and economically disadvantaged and needing protection from social injustice and exploitation. Other Backward Classes (OBC), as officially classified by the federal government, is a diverse collection of intermediate castes above the SC and $\mathrm{ST}^{(20)}$. The 'Other' social group category is a residual group which has historically enjoyed a higher status in the social hierarchy. To compute a composite proxy indicator of income, a relative index of household wealth quintile was estimated from a standard set of household assets, consumer goods and dwelling characteristics using principal component analysis ${ }^{(21)}$. Individuals were ranked on the basis of their household wealth scores and divided into wealth quintiles (from $1=$ the poorest to $5=$ the richest) ${ }^{(22)}$. If participants consumed alcohol and tobacco (smoking and smokeless) in the $30 \mathrm{~d}$ preceding the survey, they were classified as alcohol users ${ }^{(23)}$ and tobacco users ${ }^{(24)}$, respectively.

\section{Statistical approach}

Baseline sample characteristics, BMI categories, incident underweight and recovery from underweight within subgroups of the population were tabulated. The $\chi^{2}$ test was used to test differences in proportions of underweight in 2008, incident underweight and recovery from underweight by selected background characteristics. Univariate and multivariable binary logistic regression models were applied to examine predictors of underweight in 2008, incident underweight and recovery from underweight. In bivariate analysis, variables found significant at $P<0.2$ in the $\chi^{2}$ tests were included in the building of multivariate logistic regression analysis.

In multivariable regression models, the estimated coefficients may become unstable due to collinearity, resulting in inflated se. To better understand correlation among variables, correlation coefficients were estimated for all three outcome events (see online supplementary material, Supplemental Tables 1, 2 and 3). Furthermore, as linear dependencies between three or more variables may exist in the presence of small bivariate intercorrelations, variance inflation factors were also estimated to assess multicollinearity $^{(25)}$. All variance inflation factor values were less than 5.0 (Supplemental Table 4), suggesting that the possibility of high multicollinearity between analysed predictors was low.

\section{Etbics of buman subject participation}

This study was conducted by the BHDSS of the SHDS. Ethical approval was obtained from the institutional ethics review board of BHDSS. Signed informed consent from study participants was obtained prior to enrolment.

\section{Results}

Figure 1 summarizes changes in nutritional status of 6732 individuals between 2008 and 2012. In 2008, the prevalence of underweight and overweight/obesity was estimated at 46.5 and $11.5 \%$, respectively, whereas in 2012 prevalence was $39 \cdot 8$ and $16 \cdot 9 \%$, respectively. From 2008 to 2012, incident underweight was $10 \cdot 2 \%$, while recovery from underweight was $25.8 \%$. The prevalence of overweight/obesity in 2008 was $11.5 \%$, and incident overweight/obesity (from 2008 to 2012 ) was $7 \cdot 7 \%$. From 2008 to $2012,25 \cdot 8 \%$ of

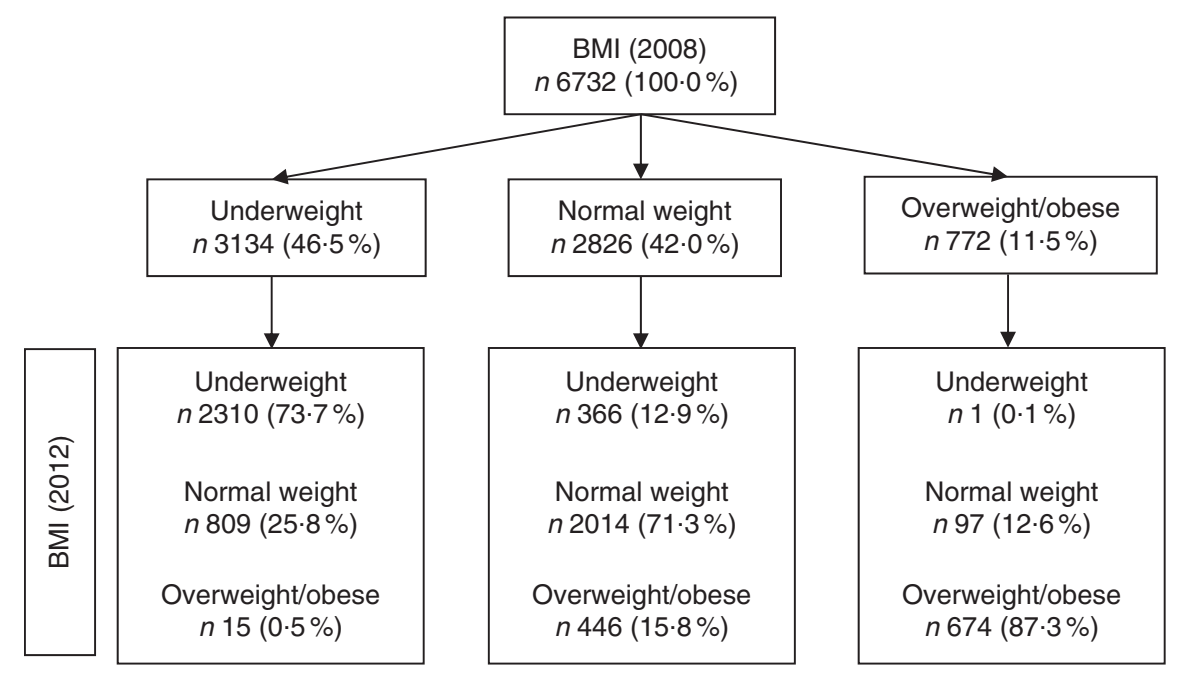

Fig. 1 Baseline distribution and dynamics of BMI categories from 2008 to 2012 among predominantly rural individuals ( $n$ 6732) aged $\geq 18$ years, Birbhum Health and Demographic Surveillance System, West Bengal, India 
Table 1 Underweight in 2008, incident underweight (transition from normal weight or overweight/obese in 2008 to underweight in 2012) and recovery from underweight (transition from underweight in 2008 to normal weight in 2012), according to baseline characteristics, among predominantly rural individuals ( $n$ 6732) aged $\geq 18$ years, Birbhum Health and Demographic Surveillance System, West Bengal, India

\begin{tabular}{|c|c|c|c|c|c|c|}
\hline \multirow[b]{2}{*}{ Baseline characteristic } & \multicolumn{2}{|c|}{$\begin{array}{l}\text { Underweight in } 2008 \\
\qquad(n \text { 6732) }\end{array}$} & \multicolumn{2}{|c|}{$\begin{array}{l}\text { Incident underweight } \\
\qquad(n \text { 3598) }\end{array}$} & \multicolumn{2}{|c|}{$\begin{array}{l}\text { Recovery from underweight } \\
\qquad(n 3134)\end{array}$} \\
\hline & $n$ & $\%$ & $n$ & $\%$ & $n$ & $\%$ \\
\hline Age (years) & \multicolumn{2}{|c|}{$x^{2}=49.7 ; P<0.001$} & \multicolumn{2}{|c|}{$x^{2}=18.2 ; P<0.001$} & \multicolumn{2}{|c|}{$x^{2}=108.0 ; P<0.001$} \\
\hline $18-24$ & $\hat{1111}$ & $16 \cdot 5$ & 543 & $15 \cdot 1$ & 568 & $18 \cdot 1$ \\
\hline $25-35$ & 2076 & 30.8 & 1153 & $32 \cdot 1$ & 923 & 29.5 \\
\hline $36-49$ & 2134 & 31.7 & 1233 & $34 \cdot 3$ & 901 & $28 \cdot 8$ \\
\hline$\geq 50$ & 1411 & $21 \cdot 0$ & 669 & $18 \cdot 6$ & 742 & 23.7 \\
\hline Sex & \multicolumn{2}{|c|}{$x^{2}=0.1 ; P=0.723$} & \multicolumn{2}{|c|}{$x^{2}=2 \cdot 6 ; P=0.103$} & \multicolumn{2}{|c|}{$X^{2}=11.8 ; P=0.001$} \\
\hline Male & 2936 & 43.6 & 1562 & $43 \cdot 4$ & 1374 & 43.8 \\
\hline Female & 3796 & $56 \cdot 4$ & 2036 & $56 \cdot 6$ & 1760 & $56 \cdot 2$ \\
\hline Marital status & \multicolumn{2}{|c|}{$x^{2}=7.1 ; P=0.029$} & \multicolumn{2}{|c|}{$x^{2}=3.5 ; P=0.177$} & \multicolumn{2}{|c|}{$X^{2}=27.3 ; P<0.001$} \\
\hline Never married & 469 & $7 \cdot 0$ & $\hat{2} 23$ & 6.2 & $\hat{24} 6$ & 7.9 \\
\hline Married & 5595 & 83.1 & 3013 & 83.7 & 2582 & $82 \cdot 4$ \\
\hline Widow/widower/divorced/separated & 668 & 9.9 & 362 & $10 \cdot 1$ & 306 & $9 \cdot 8$ \\
\hline Highest grade of education attained & \multicolumn{2}{|c|}{$x^{2}=211.2 ; P<0.001$} & \multicolumn{2}{|c|}{$X^{2}=48.1 ; P<0.001$} & \multicolumn{2}{|c|}{$x^{2}=35.7 ; P<0.001$} \\
\hline Illiterate & 2817 & 41.8 & $\hat{1276}$ & 35.5 & 1541 & $49 \cdot 2$ \\
\hline $1-5$ & 1365 & 20.3 & 704 & $19 \cdot 6$ & 661 & $21 \cdot 1$ \\
\hline $6-10$ & 1960 & 29.1 & 1184 & $32 \cdot 9$ & 776 & $24 \cdot 8$ \\
\hline$\geq 11$ & 590 & 8.8 & 434 & $12 \cdot 1$ & 156 & 5.0 \\
\hline Employment & $x^{2}=4$ & .001 & $x^{2}=1$ & .001 & $x^{2}=$ & 001 \\
\hline Unemployed & 3319 & $49 \cdot 3$ & $\hat{1816}$ & 50.5 & $1 \hat{503}$ & $48 \cdot 0$ \\
\hline Primary & 3013 & 44.8 & 1510 & $42 \cdot 0$ & 1503 & 48.0 \\
\hline Secondary/tertiary & 400 & 5.9 & 272 & 7.6 & 128 & $4 \cdot 1$ \\
\hline Social group & $x^{2}=12$ & 0.001 & $x^{2}=9$ & .001 & $x^{2}=$ & 001 \\
\hline Scheduled Caste & 2274 & 33.8 & $\hat{1022}$ & 28.4 & 1252 & $40 \cdot 0$ \\
\hline Scheduled Tribe & 543 & 8.1 & 261 & $7 \cdot 3$ & 282 & 9.0 \\
\hline Other Backward Classes & 487 & $7 \cdot 2$ & 268 & 7.5 & 219 & $7 \cdot 0$ \\
\hline Other & 3428 & 50.9 & 2047 & $56 \cdot 9$ & 1381 & $44 \cdot 1$ \\
\hline Religion & $x^{2}=3$ & .001 & $x^{2}=6$ & 010 & $x^{2}=$ & 001 \\
\hline Hindu & 4678 & 69.5 & 2392 & $66 \cdot 5$ & 2286 & 72.9 \\
\hline Muslim or other & 2054 & 30.5 & 1206 & 33.5 & 848 & $27 \cdot 1$ \\
\hline Wealth quintile & $x^{2}=37$ & 0.001 & $x^{2}=6$ & .001 & $x^{2}=$ & 002 \\
\hline Poorest & 1423 & $21 \cdot 1$ & 583 & $16 \cdot 2$ & 840 & $26 \cdot 8$ \\
\hline Poorer & 1190 & $17 \cdot 7$ & 538 & $15 \cdot 0$ & 652 & $20 \cdot 8$ \\
\hline Middle & 1281 & $19 \cdot 0$ & 647 & $18 \cdot 0$ & 634 & $20 \cdot 2$ \\
\hline Richer & 1446 & 21.5 & 796 & $22 \cdot 1$ & 650 & $20 \cdot 7$ \\
\hline Richest & 1392 & 20.7 & 1034 & 28.7 & 358 & 11.4 \\
\hline Block of residence & $x^{2}=5$ & .001 & $x^{2}=3$ & 311 & $x^{2}=$ & 56 \\
\hline Mohammad Bazar & $\hat{2} 003$ & 29.8 & 1070 & $29 \cdot 7$ & $9 \hat{3} 3$ & 29.8 \\
\hline Rajnagar & 721 & 10.7 & 348 & $9 \cdot 7$ & 373 & 11.9 \\
\hline Sainthia & 2621 & 38.9 & 1322 & $36 \cdot 7$ & 1299 & 41.5 \\
\hline Suri I & 1387 & 20.6 & 858 & 23.9 & 529 & $16 \cdot 9$ \\
\hline Alcohol use & $x^{2}=7$ & 006 & $x^{2}=2$ & .001 & $x^{2}=$ & 001 \\
\hline No & 6334 & 94.1 & 3412 & 94.8 & 2922 & 93.2 \\
\hline Yes & 398 & 5.9 & 186 & $5 \cdot 2$ & 212 & $6 \cdot 8$ \\
\hline Smoking & $x^{2}=3$ & .001 & $x^{2}=2$ & .001 & $x^{2}=$ & 001 \\
\hline No & 5350 & 79.5 & 2961 & $82 \cdot 3$ & 2389 & $76 \cdot 2$ \\
\hline Yes & 1382 & 20.5 & 637 & 17.7 & 745 & 23.8 \\
\hline Smokeless tobacco use & $x^{2}=3$ & 073 & $x^{2}=0$ & 624 & $x^{2}=$ & 001 \\
\hline No & 5329 & 79.2 & 2878 & $80 \cdot 0$ & $2 \hat{451}$ & $78 \cdot 2$ \\
\hline Yes & 1403 & $20 \cdot 8$ & 720 & $20 \cdot 0$ & 683 & $21 \cdot 8$ \\
\hline Health insurance & $x^{2}=3$ & .001 & $x^{2}=2$ & 269 & $x^{2}=$ & 90 \\
\hline No & 4563 & 67.8 & 2556 & $71 \cdot 0$ & 2007 & 64.0 \\
\hline Public insurance & 2103 & 31.2 & 1016 & 28.2 & 1087 & 34.7 \\
\hline Private insurance & 66 & 1.0 & 26 & 0.7 & 40 & 1.3 \\
\hline Illness (last $30 \mathrm{~d}$ ) & & & $x^{2}=2$ & 328 & $x^{2}=$ & 003 \\
\hline No & & & 2834 & $78 \cdot 8$ & 2375 & $75 \cdot 8$ \\
\hline Acute & & & 543 & $15 \cdot 1$ & 560 & $17 \cdot 9$ \\
\hline Chronic & & & 221 & $6 \cdot 1$ & 199 & 6.4 \\
\hline
\end{tabular}

Percentages may not add to 100 due to rounding.

*Information on illness during $30 \mathrm{~d}$ preceding the survey was not collected in 2008.

underweight individuals recovered, $12 \cdot 9 \%$ of normal-weight individuals became underweight and $0 \cdot 1 \%$ of overweight/ obese individuals became underweight.
In Table 1 , baseline characteristics of the study population, prevalence of underweight in 2008 and incident/ recovery from underweight between 2008 and 2012 are 
presented. Of the total sample in $2008,62.5 \%$ of participants were aged 25-49 years, $41.8 \%$ were illiterate and $49.3 \%$ were unemployed. Of underweight persons at baseline, $49.2 \%$ were illiterate. The prevalence of smoking and smokeless tobacco use was higher than that of alcohol consumption across categories of outcome events.

There were no missing data for any predictor variable. In the $\chi^{2}$ test for associations with underweight in 2008 , sex had a $P$ value of more than $0 \cdot 2$. The $\chi^{2}$ test for variables associated with incident underweight indicated that all the variables were associated at $P<0 \cdot 2$ except for the block of residence, smokeless tobacco use, health insurance availability, and illness in the $30 \mathrm{~d}$ preceding the survey. Similarly, all variables except block of residence were associated with recovery from underweight at $P<0 \cdot 2$.

The unadjusted and adjusted odds, with $95 \%$ CI, of underweight in 2008, incident underweight from 2008 to 2012, and recovery from underweight from 2008 to 2012 are presented in Tables 2, 3 and 4, respectively. Compared with people aged 18-24 years, people aged 36-49 years had lower adjusted odds of underweight in 2008 (OR= $0.65 ; 95 \%$ CI $0.55,0.77 ; P<0.001)$, incident underweight $(\mathrm{OR}=0.58 ; 95 \%$ CI $0.40,0.85 ; P=0.005)$ and recovery from underweight $(\mathrm{OR}=0.56 ; 95 \%$ CI $0.43, \quad 0.74$; $P<0.001)$. Compared with those who were illiterate, people with a Grade 6 education or higher had lower adjusted odds of underweight in 2008 and incident underweight, and higher adjusted odds of recovery from underweight. People belonging to ST had increased adjusted odds of incident underweight ( OR $=2 \cdot 44 ; 95 \% \mathrm{CI}$ 1.55, 3.23; $P<0.001)$ compared with SC. Muslims had lower adjusted odds of underweight (OR $=0 \cdot 67 ; 95 \% \mathrm{CI}$ $0.57,0.78 ; P<0.001)$ and higher odds of recovery from underweight $(\mathrm{OR}=1.47 ; 95 \%$ CI 1.15, 1.89; $P=0.002)$ compared with Hindus. Adjusted odds of underweight in 2008 were lower among people of the middle, richer and richest wealth quintiles, whereas the richest had lower adjusted odds of incident underweight than the poorest (OR=0.58; 95\% CI 0.38, 0.90; $P=0.014)$. Current consumption of alcohol was negatively associated with underweight in 2008 (OR=0.76; 95\% CI 0.60, 0.97; $P=0.028)$, whereas smoking was associated with increased adjusted odds of underweight $(\mathrm{OR}=1 \cdot 42 ; 95 \%$ CI 1.23, 1.63; $P<0.001)$ and incident underweight $(\mathrm{OR}=$ $1.76 ; 95 \%$ CI $1.26,2.47 ; P=0.001$ ). The rate of recovery was higher among individuals suffering from acute illness during the $30 \mathrm{~d}$ prior to the 2012 survey wave $(\mathrm{OR}=1 \cdot 25$; $95 \%$ CI $1.01,1.55 ; P=0.037)$ than among people who reported no illness.

\section{Discussion}

Using prospective cohort data from a Health and Demographic Surveillance System in Birbhum, West Bengal,
India, a high burden of underweight (46.5\%) for adults was estimated in 2008. According to the 2015-16 National Family Health Survey (NFHS) conducted in West Bengal ${ }^{(26)}$, the prevalence of underweight among men and women aged 15-49 years was 19.9 and $21.3 \%$, respectively, which is a substantial reduction from NFHS 2005-06 estimates (35.2 and $39.1 \%$ for men and women, respectively). In our rural setting in Birbhum, we recorded a modest decline in underweight to nearly $40 \%$ in 2012 .

Findings reveal that the odds of underweight in 2008 and incident underweight were lower in the 25-35 and 36-49 years age groups, as compared with people of the 18-24 years age group, whereas odds of recovery from underweight were lower in the 36-49 and $\geq 50$ years age groups, indicating that changes in BMI are less volatile as age advances ${ }^{(27)}$. Studies have documented that BMI change in later adulthood has less to do with age than with social, environmental and cultural conditions that significantly influence energy consumption ${ }^{(28,29)}$. The present analysis also reveals that people who experienced acute illness in the $30 \mathrm{~d}$ preceding the 2012 survey date had higher odds of recovery from underweight. This could be attributed to the care and comfort received by these individuals during the treatment of their illness (e.g. food and nutrient supplementation, long period of resting, medication). However, this finding warrants further investigation. Having health insurance did not appear to have any bearing on recovery from underweight in the present study. This may be due to that fact that having insurance does not guarantee better access to or quality of care, and that the operational definition of the insurance variable was therefore inadequate. In addition, the majority of people in the study population have public health insurance that covers costs of hospitalization but covers only selected medicines, which do not include nutritional or food supplements. The study also reveals that smokers were more likely to experience underweight in 2008 and incident underweight than non-smokers, whereas recovery from underweight was not associated with smoking status. This finding is supported by local evidence from a study conducted in an urban Indian population, which indicated that any type of smoking could be a risk factor for underweight ${ }^{(30)}$, as well as international studies that have explored the complex pathways of smoking-related physiological changes (direct pathways affecting appetite or other aspects of physiology, or indirect pathways decreasing the amount of money available for food) which might increase the probability of underweight ${ }^{(31)}$. Studies of the same population indicated that the joint effect of underweight and smoking could be especially deleterious to human health ${ }^{(32)}$. In our study, alcohol users were less likely to be underweight compared with non-users, which also concurs with other studies in India ${ }^{(33)}$ and elsewhere ${ }^{(34)}$ that show alcohol consumption could increase the risk of overweight and obesity. 
Table 2 Predictors of underweight in 2008 among predominantly rural individuals ( $n$ 6732) aged $\geq 18$ years, Birbhum Health and Demographic Surveillance System, West Bengal, India

\begin{tabular}{|c|c|c|c|c|c|c|c|}
\hline & \multirow[b]{3}{*}{$\begin{array}{l}\text { No. of events } \\
\quad(n 3134)\end{array}$} & \multicolumn{6}{|c|}{ Underweight in 2008} \\
\hline & & \multicolumn{3}{|c|}{ Unadjusted } & \multicolumn{3}{|c|}{ Adjusted } \\
\hline & & OR & $95 \% \mathrm{Cl}$ & $P$ & OR & $95 \% \mathrm{Cl}$ & $P$ \\
\hline \multicolumn{8}{|l|}{ Age (years) } \\
\hline $18-24$ & 568 & 1.00 & Ref. & & 1.00 & Ref. & \\
\hline $25-35$ & 923 & 0.77 & $0.66,0.89$ & $<0.001$ & 0.71 & $0.60,0.84$ & $<0.001$ \\
\hline $36-49$ & 901 & 0.70 & $0.60,0.81$ & $<0.001$ & 0.65 & $0.55,0.77$ & $<0.001$ \\
\hline$\geq 50$ & 742 & 1.06 & $0.91,1.24$ & 0.466 & 0.98 & $0.80,1.18$ & 0.798 \\
\hline \multicolumn{8}{|l|}{ Marital status } \\
\hline Never married & 246 & 1.00 & Ref. & & 1.00 & Ref. & \\
\hline Married & 2582 & 0.78 & $0.64,0.94$ & 0.009 & 1.00 & $0.81,1.23$ & 0.973 \\
\hline Widow/widower/divorced/separated & 306 & 0.77 & $0.60,0.97$ & 0.027 & $1 \cdot 13$ & $0.85,1.50$ & 0.399 \\
\hline \multicolumn{8}{|l|}{ Highest grade of education attained } \\
\hline Illiterate & 1541 & 1.00 & Ref. & & 1.00 & Ref. & \\
\hline $1-5$ & 661 & 0.78 & $0.68,0.88$ & $<0.001$ & 0.85 & $0.74,0.98$ & 0.022 \\
\hline $6-10$ & 776 & 0.54 & $0.48,0.61$ & $<0.001$ & 0.68 & $0.59,0.79$ & $<0.001$ \\
\hline$\geq 11$ & 156 & 0.30 & $0.24,0.36$ & $<0.001$ & 0.50 & $0.39,0.64$ & $<0.001$ \\
\hline \multicolumn{8}{|l|}{ Employment } \\
\hline Unemployed & 1503 & 1.00 & Ref. & & 1.00 & Ref. & \\
\hline Primary & 1503 & 1.20 & $1.09,1.33$ & $<0.001$ & 0.97 & $0.86,1.09$ & 0.559 \\
\hline Secondary/tertiary & 128 & 0.57 & $0.46,0.71$ & $<0.001$ & 0.75 & $0.59,0.96$ & 0.055 \\
\hline \multicolumn{8}{|l|}{ Social group } \\
\hline Scheduled Caste & 1252 & 1.00 & Ref. & & 1.00 & Ref. & \\
\hline Scheduled Tribe & 282 & 0.88 & $0.73,1.06$ & 0.189 & 0.86 & $0.70,1.06$ & 0.156 \\
\hline Other Backward Classes & 219 & 0.67 & $0.55,0.81$ & $<0.001$ & $1 \cdot 17$ & $0.93,1.47$ & $0 \cdot 182$ \\
\hline Other & 1381 & 0.55 & $0.49,0.61$ & $<0.001$ & 1.01 & $0.86,1.18$ & 0.925 \\
\hline \multicolumn{8}{|l|}{ Religion } \\
\hline Hindu & 2286 & 1.00 & Ref. & & 1.00 & Ref. & \\
\hline Muslim or other & 848 & 0.74 & $0.66,0.82$ & $<0.001$ & 0.67 & $0.57,0.78$ & $<0.001$ \\
\hline \multicolumn{8}{|l|}{ Wealth quintile } \\
\hline Poorest & 840 & 1.00 & Ref. & & 1.00 & Ref. & \\
\hline Poorer & 652 & 0.84 & $0.72,0.98$ & 0.029 & 0.88 & $0.75,1.03$ & 0.119 \\
\hline Middle & 634 & 0.68 & $0.58,0.79$ & $<0.001$ & 0.73 & $0.62,0.86$ & $<0.001$ \\
\hline Richer & 650 & 0.57 & $0.49,0.66$ & $<0.001$ & 0.67 & $0.57,0.79$ & $<0.001$ \\
\hline Richest & 358 & 0.24 & $0.20,0.28$ & $<0.001$ & 0.31 & $0.26,0.38$ & $<0.001$ \\
\hline \multicolumn{8}{|l|}{ Block of residence } \\
\hline Mohammad Bazar & 933 & 1.00 & Ref. & & 1.00 & Ref. & \\
\hline Rajnagar & 373 & 1.23 & $1.04,1.46$ & 0.018 & $1 \cdot 10$ & $0.92,1.33$ & 0.300 \\
\hline Sainthia & 1299 & $1 \cdot 13$ & $1.00,1.27$ & 0.044 & 1.03 & $0.91,1.17$ & 0.633 \\
\hline Suri I & 529 & 0.71 & $0.62,0.81$ & $<0.001$ & 0.75 & $0.65,0.88$ & $<0.001$ \\
\hline \multicolumn{8}{|l|}{ Alcohol use } \\
\hline No & 2922 & 1.00 & Ref. & & 1.00 & Ref. & \\
\hline Yes & 212 & 1.33 & $1.09,1.63$ & 0.006 & 0.76 & $0.60,0.97$ & 0.028 \\
\hline \multicolumn{8}{|l|}{ Smoking } \\
\hline No & 2389 & 1.00 & Ref. & & 1.00 & Ref. & \\
\hline Yes & 745 & 1.45 & $1.29,1.63$ & $<0.001$ & 1.42 & $1.23,1.63$ & $<0.001$ \\
\hline \multicolumn{8}{|l|}{ Smokeless tobacco use } \\
\hline No & 2451 & 1.00 & Ref. & & 1.00 & Ref. & \\
\hline Yes & 683 & $1 \cdot 11$ & $0.99,1.25$ & 0.073 & 1.00 & $0.88,1.14$ & 0.962 \\
\hline \multicolumn{8}{|l|}{ Health insurance } \\
\hline No & 2007 & 1.00 & Ref. & & 1.00 & Ref. & \\
\hline Public insurance & 1087 & 1.36 & $1.23,1.51$ & $<0.001$ & 0.99 & $0.88,1.11$ & 0.819 \\
\hline Private insurance & 40 & 1.96 & $1.19,3.22$ & 0.008 & 2.38 & $1.37,4.13$ & 0.052 \\
\hline
\end{tabular}

Ref., reference category.

'Adjusted' models are adjusted for all variables found significant at $P<0.2$ in $X^{2}$ tests (Table 1).

The current results indicate that with increasing years of education, the prevalence of underweight in 2008 (Grade 1 or higher) and incident underweight (Grade 6 or higher) was likely to decrease, and the recovery from underweight was likely to increase with education (Grade 6 or higher). Educated people are expected to be relatively more aware of their nutrition than the uneducated ${ }^{(35)}$, which may increases their chances of recovery from underweight. The observed effect of education could also be due to residual confounding by wealth. Even after controlling for wealth, education is related to better life choices in general ${ }^{(8)}$, not just knowledge of normal BMI, and such choices may inevitably lead to improved nutrition. Social group appeared to be a significant predictor of recovery from underweight. As compared with people from the SC community, ST had higher odds of incidence of 
Table 3 Predictors of incident underweight (transition from normal weight or overweight/obese in 2008 to underweight in 2012) among predominantly rural individuals $(n 6732)$ aged $\geq 18$ years, Birbhum Health and Demographic Surveillance System, West Bengal, India

\begin{tabular}{|c|c|c|c|c|c|c|c|}
\hline & \multirow[b]{3}{*}{$\begin{array}{l}\text { No. of events } \\
\quad(n 367)\end{array}$} & \multicolumn{6}{|c|}{ Incident underweight } \\
\hline & & \multicolumn{3}{|c|}{ Unadjusted } & \multicolumn{3}{|c|}{ Adjusted } \\
\hline & & OR & $95 \% \mathrm{Cl}$ & $P$ & OR & $95 \% \mathrm{Cl}$ & $P$ \\
\hline \multicolumn{8}{|l|}{ Age (years) } \\
\hline $18-24$ & 78 & 1.00 & Ref. & & 1.00 & Ref. & \\
\hline $25-35$ & 105 & 0.60 & $0.44,0.82$ & 0.001 & 0.61 & $0.43,0.87$ & 0.006 \\
\hline $36-49$ & 104 & 0.55 & $0.40,0.75$ & $<0.001$ & 0.58 & $0.40,0.85$ & 0.005 \\
\hline$\geq 50$ & 80 & 0.81 & $0.58,1.13$ & 0.217 & 0.82 & $0.55,1.24$ & 0.348 \\
\hline \multicolumn{8}{|l|}{ Sex } \\
\hline Male & 174 & 1.00 & Ref. & & 1.00 & Ref. & \\
\hline Female & 193 & 0.84 & $0.67,1.04$ & 0.103 & 0.84 & $0.59,1.19$ & 0.321 \\
\hline \multicolumn{8}{|l|}{ Marital status } \\
\hline Never married & 21 & 1.00 & Ref. & & 1.00 & Ref. & \\
\hline Married & 299 & 1.06 & $0.67,1.69$ & 0.807 & 1.37 & $0.83,2 \cdot 26$ & 0.220 \\
\hline Widow/widower/divorced/separated & 47 & 1.44 & $0.83,2.47$ & 0.193 & 1.84 & $0.96,3.52$ & 0.066 \\
\hline \multicolumn{8}{|l|}{ Highest grade of education attained } \\
\hline Illiterate & 181 & 1.00 & Ref. & & 1.00 & Ref. & \\
\hline $1-5$ & 78 & 0.75 & $0.57,1.00$ & 0.050 & 0.80 & $0.59,1.09$ & 0.162 \\
\hline $6-10$ & 89 & 0.49 & $0.38,0.64$ & $<0.001$ & 0.60 & $0.43,0.84$ & 0.003 \\
\hline$\geq 11$ & 19 & 0.28 & $0.17,0.45$ & $<0.001$ & 0.36 & $0.20,0.65$ & 0.001 \\
\hline \multicolumn{8}{|l|}{ Employment } \\
\hline Unemployed & 171 & 1.00 & Ref. & & 1.00 & Ref. & \\
\hline Primary & 182 & 1.32 & $1.06,1.64$ & 0.014 & 0.79 & $0.58,1.07$ & 0.133 \\
\hline Secondary/tertiary & 14 & 0.52 & $0.30,0.91$ & 0.023 & 0.61 & $0.33,1.13$ & 0.116 \\
\hline \multicolumn{8}{|l|}{ Social group } \\
\hline Scheduled Caste & 132 & 1.00 & Ref. & & 1.00 & Ref. & \\
\hline Scheduled Tribe & 65 & $2 \cdot 24$ & $1 \cdot 60,3.13$ & $<0.001$ & $2 \cdot 24$ & $1.55,3.23$ & $<0.001$ \\
\hline Other Backward Classes & 13 & 0.34 & $0.19,0.62$ & $<0.001$ & 0.59 & $0.32,1.10$ & 0.098 \\
\hline Other & 157 & 0.56 & $0.44,0.72$ & $<0.001$ & 0.86 & $0.60,1.23$ & 0.402 \\
\hline \multicolumn{8}{|l|}{ Religion } \\
\hline Hindu & 266 & 1.00 & Ref. & & 1.00 & Ref. & \\
\hline Muslim or other & 101 & 0.73 & $0.57,0.93$ & 0.010 & 0.76 & $0.54,1.08$ & 0.124 \\
\hline \multicolumn{8}{|l|}{ Wealth quintile } \\
\hline Poorest & 86 & 1.00 & Ref. & & 1.00 & Ref. & \\
\hline Poorer & 62 & 0.75 & $0.53,1.07$ & 0.112 & 0.79 & $0.55,1.14$ & 0.206 \\
\hline Middle & 96 & 1.01 & $0.73,1.38$ & 0.966 & $1 \cdot 19$ & $0.86,1.65$ & 0.302 \\
\hline Richer & 71 & 0.57 & $0.41,0.79$ & 0.001 & 0.86 & $0.60,1.23$ & 0.398 \\
\hline Richest & 52 & 0.31 & $0.21,0.44$ & $<0.001$ & 0.58 & $0.38,0.90$ & 0.014 \\
\hline \multicolumn{8}{|l|}{ Alcohol use } \\
\hline No & 329 & 1.00 & Ref. & & 1.00 & Ref. & \\
\hline Yes & 38 & $2 \cdot 41$ & $1.66,3.50$ & $<0.001$ & 0.82 & $0.52,1.29$ & 0.383 \\
\hline \multicolumn{8}{|l|}{ Smoking } \\
\hline No & 270 & 1.00 & Ref. & & 1.00 & Ref. & \\
\hline Yes & 97 & 1.79 & $1 \cdot 39,2 \cdot 30$ & $<0.001$ & 1.76 & $1.26,2.47$ & 0.001 \\
\hline
\end{tabular}

Ref., reference category.

'Adjusted' models are adjusted for all variables found significant at $P<0.2$ in $X^{2}$ tests (Table 1).

underweight. ST are considered the most underserved among social groups with limited or no access to productive resources. Persistent discrimination in several other domains of social and economic status ${ }^{(36)}$, which can also be attributed to their food insecurity, may explain their higher probability of being underweight. With lower odds of being underweight in 2008, recovery from underweight was higher among Muslims than Hindus. Animal-based protein intake is known to have a better impact on nutritional status in the short term ${ }^{(37)}$. Therefore, one could expect a low prevalence and better recovery status among Muslims whose consumption of meat is relatively higher compared with Hindus ${ }^{(38)}$. Economic status was also associated with underweight status: compared with the poorest quintile of wealth, the middle, richer and richest economic groups had lower odds of being underweight in 2008, and the richest quintile had lower odds of incident underweight. However, recovery from underweight was not affected by wealth quintile. Poverty is associated with increased odds of underweight ${ }^{(35)}$ and economically better-off individuals are more likely to gain weight in India ${ }^{(13)}$. Poverty restricts access to food to meet daily requirements or ensure dietary diversity, which could lead to undernutrition ${ }^{(39)}$. During epidemiological transition, changing food consumption and physical activity patterns that have led to 
Table 4 Predictors of recovery from underweight (transition from underweight in 2008 to normal weight in 2012) among predominantly rural individuals ( $n 6732$ ) aged $\geq 18$ years, Birbhum Health and Demographic Surveillance System, West Bengal, India

\begin{tabular}{|c|c|c|c|c|c|c|c|}
\hline & \multirow[b]{3}{*}{$\begin{array}{l}\text { No. of events } \\
(n \text { 809) }\end{array}$} & \multicolumn{6}{|c|}{ Recovery from underweight } \\
\hline & & \multicolumn{3}{|c|}{ Unadjusted } & \multicolumn{3}{|c|}{ Adjusted } \\
\hline & & OR & $95 \% \mathrm{Cl}$ & $P$ & OR & $95 \% \mathrm{Cl}$ & $P$ \\
\hline \multicolumn{8}{|l|}{ Age (years) } \\
\hline $18-24$ & 214 & 1.00 & Ref. & & 1.00 & Ref. & \\
\hline $25-35$ & 286 & 0.74 & $0.60,0.93$ & 0.008 & 0.83 & $0.65,1.06$ & 0.140 \\
\hline $36-49$ & 199 & 0.47 & $0.37,0.59$ & $<0.001$ & 0.56 & $0.43,0.74$ & $<0.001$ \\
\hline$\geq 50$ & 110 & 0.29 & $0.22,0.37$ & $<0.001$ & 0.36 & $0.26,0.50$ & $<0.001$ \\
\hline \multicolumn{8}{|l|}{ Sex } \\
\hline Male & 313 & 1.00 & Ref. & & 1.00 & Ref. & \\
\hline Female & 496 & 1.33 & $1.13,1.57$ & 0.001 & 1.23 & $0.94,1.60$ & 0.132 \\
\hline \multicolumn{8}{|l|}{ Marital status } \\
\hline Never married & 41 & 1.00 & Ref. & & 1.00 & Ref. & \\
\hline Married & 658 & 1.71 & $1 \cdot 21,2.42$ & 0.002 & 1.07 & $0.73,1.58$ & 0.721 \\
\hline Widow/widower/divorced/separated & 110 & $2 \cdot 81$ & $1.86,4.22$ & $<0.001$ & $1 \cdot 15$ & $0.70,1.89$ & 0.572 \\
\hline \multicolumn{8}{|l|}{ Highest grade of education attained } \\
\hline Illiterate & 345 & 1.00 & Ref. & & 1.00 & Ref. & \\
\hline $1-5$ & 159 & $1 \cdot 10$ & $0.89,1.36$ & 0.394 & 0.90 & $0.71,1.13$ & 0.370 \\
\hline $6-10$ & 247 & 1.62 & $1.33,1.96$ & $<0.001$ & 1.29 & $1.02,1.65$ & 0.037 \\
\hline$\geq 11$ & 58 & $2 \cdot 05$ & $1.45,2.90$ & $<0.001$ & 1.59 & $1 \cdot 02,2 \cdot 48$ & 0.040 \\
\hline \multicolumn{8}{|l|}{ Employment } \\
\hline Unemployed & 432 & 1.00 & Ref. & & 1.00 & Ref. & \\
\hline Primary & 351 & 0.76 & $0.64,0.89$ & 0.001 & 1.01 & $0.81,1.26$ & 0.915 \\
\hline Secondary/tertiary & 26 & 0.63 & $0.41,0.99$ & 0.043 & 0.73 & $0.45,1.19$ & 0.203 \\
\hline \multicolumn{8}{|l|}{ Social group } \\
\hline Scheduled Caste & 290 & 1.00 & Ref. & & 1.00 & Ref. & \\
\hline Scheduled Tribe & 52 & 0.75 & $0.54,1.04$ & 0.086 & 0.84 & $0.59,1.19$ & 0.320 \\
\hline Other Backward Classes & 66 & 1.43 & $1.04,1.96$ & 0.027 & $1 \cdot 19$ & $0.82,1.73$ & 0.349 \\
\hline Other & 401 & 1.36 & $1.14,1.62$ & 0.001 & 0.99 & $0.76,1.29$ & 0.954 \\
\hline \multicolumn{8}{|l|}{ Religion } \\
\hline Hindu & 544 & 1.00 & Ref. & & 1.00 & Ref. & \\
\hline Muslim or other & 265 & 1.46 & $1.22,1.73$ & $<0.001$ & 1.47 & $1.15,1.89$ & 0.002 \\
\hline \multicolumn{8}{|l|}{ Wealth quintile } \\
\hline Poorest & 193 & 1.00 & Ref. & & 1.00 & Ref. & \\
\hline Poorer & 155 & 1.05 & $0.82,1.33$ & 0.718 & 1.01 & $0.79,1.29$ & 0.949 \\
\hline Middle & 154 & 1.08 & $0.84,1.37$ & 0.556 & 1.03 & $0.80,1.32$ & 0.845 \\
\hline Richer & 199 & 1.48 & $1.17,1.86$ & 0.001 & 1.27 & $0.98,1.64$ & 0.068 \\
\hline Richest & 108 & 1.45 & $1 \cdot 10,1.91$ & 0.009 & $1 \cdot 20$ & $0.85,1.69$ & 0.305 \\
\hline \multicolumn{8}{|l|}{ Alcohol use } \\
\hline No & 782 & 1.00 & Ref. & & 1.00 & Ref. & \\
\hline Yes & 27 & 0.40 & $0.26,0.60$ & $<0.001$ & 0.79 & $0.50,1.25$ & 0.311 \\
\hline \multicolumn{8}{|l|}{ Smoking } \\
\hline No & 674 & 1.00 & Ref. & & 1.00 & Ref. & \\
\hline Yes & 135 & 0.56 & $0.46,0.69$ & $<0.001$ & 0.85 & $0.65,1.11$ & 0.237 \\
\hline \multicolumn{8}{|l|}{ Smokeless tobacco use } \\
\hline No & 666 & 1.00 & Ref. & & 1.00 & Ref. & \\
\hline Yes & 143 & 0.71 & $0.58,0.87$ & 0.001 & 0.92 & $0.74,1.16$ & 0.494 \\
\hline \multicolumn{8}{|l|}{ Health insurance } \\
\hline No & 543 & 1.00 & Ref. & & 1.00 & Ref. & \\
\hline Public insurance & 255 & 0.83 & $0.70,0.98$ & 0.029 & 0.92 & $0.77,1.11$ & 0.411 \\
\hline Private insurance & 11 & 1.02 & $0.51,2.06$ & 0.950 & 1.04 & $0.48,2.24$ & 0.922 \\
\hline \multicolumn{8}{|l|}{ Illness (last $30 \mathrm{~d}$ ) } \\
\hline No & 607 & 1.00 & Ref. & & 1.00 & Ref. & \\
\hline Acute & 167 & 1.24 & $1.01,1.52$ & 0.040 & 1.25 & $1.01,1.55$ & 0.037 \\
\hline Chronic & 35 & 0.62 & $0.43,0.91$ & 0.013 & 0.70 & $0.48,1.04$ & 0.077 \\
\hline
\end{tabular}

Ref., reference category.

'Adjusted' models are adjusted for all variables found significant at $P<0.2$ in $X^{2}$ tests (Table 1).

increasing sedentarism, especially among wealthy people, have contributed to the rise of an obesity epidemic ${ }^{(40)}$.

The results of the present study should be interpreted in the light of its limitations. First, data on dietary intake would have provided more insight in understanding change in nutritional status. Second, the predictors of prevalence, incident and recovery from overweight/ obesity were not assessed in the study and have been reserved for future analysis. Also, a more comprehensive characterization of dynamics in nutritional status (from 
undernutrition to overnutrition) was deemed insufficient with existing data. Third, the study included only anthropometric measurements (BMI) as an indicator of undernutrition and excluded biochemical or clinical indicators (e.g. iron-deficiency anaemia) or social indicators (e.g. food security or dietary diversity) of undernutrition. Fourth, as it is an observational study, our results are inevitably affected by an intractable measure of confounding. Despite these limitations, the availability of a large sample size and absence of missing data in predictor variables have brought more power to the study, while prospective assessment of the issue helped strengthen the study findings.

\section{Conclusion}

In conclusion, a high burden of underweight was found in the study population. An urgent need for local nutrition interventions to curb the level of underweight is warranted. While designing an intervention, focusing on improving nutrition education could be an effective strategy ${ }^{(41)}$, as adjusted odds of recovery from underweight was more likely among educated people. However, a careful measure of intervention with both wealth and education might be needed, as the effect of education on nutrition could be subject to residual confounding by an individual's income. Wealth provides resources to secure food while education is needed to better utilize health care, increase dietary diversity, improve household sanitation and hygiene, and make better overall health choices. The intervention could have some special arms to it, such as counselling for quitting smoking, which could also prove effective in curbing the level of underweight in this community. Programmes could incorporate modification of risk factors into new or existing conventional nutrition interventions (such as culturally sensitive food supplementation), targeting those subgroups in which the incidence of malnutrition is particularly high.

\section{Acknowledgements}

Financial support: This work was supported by the West Bengal State Department of Health and Family Welfare, India (memo number HF/O/MERT/1464/HSL (MISC) - 35/ 2008). The funders had no role in the design/conduct of the study, collection/analysis/interpretation of the data and preparation/review/approval of the manuscript. Conflict of interest: None. Authorship: R.K.R. and W.W.F. conceived and designed the study. R.K.R. performed the analysis. R.K.R. and S.B. prepared the first draft. W.W.F., A.B. and A.C. reviewed results and contributed in finalizing the report. All authors approved the study. Ethics of buman subject participation: This study was conducted by the BHDSS of the SHDS. Ethical approval was obtained from the institutional ethics review board of BHDSS. signed informed consent from study participants was obtained prior to enrolment.

\section{Supplementary material}

To view supplementary material for this article, please visit https://doi.org/10.1017/S1368980017003081

\section{References}

1. Kapoor SK \& Anand K (2002) Nutritional transition: a public health challenge in developing countries. $J$ Epidemiol Community Health 56, 804-805.

2. Subramanian SV, Perkins JM \& Khan KT (2009) Do burdens of underweight and overweight coexist among lower socioeconomic groups in India? Am J Clin Nutr 90, 369-376.

3. Patil YP \& Shinde RL (2014) Undernutrition among Indian men: a study based on NFHS-3. Am J Mens Health $\mathbf{8}$, 492-502.

4. Sengupta A, Angeli F, Syamala TS et al. (2015) Overweight and obesity prevalence among Indian women by place of residence and socio-economic status: contrasting patterns from 'underweight states' and 'overweight states' of India. Soc Sci Med 138, 161-169.

5. Jose S (2011) Adult undernutrition in India: is there a huge gender gap? Econ Polit Wkly 46, 95-102.

6. Deaton A \& Drèze J (2009) Food and nutrition in India: facts and interpretations. Econ Polit Wkly 44, 42-65.

7. Planning Commission (2011) Addressing India's Nutrition Challenges: Report of the Multistakeholder Retreat. New Delhi: Planning Commission, Government of India.

8. Drèze J \& Sen A (2013) An Uncertain Glory: India and its Contradictions. London: Allen Lane.

9. Rai RK (2015) Factors associated with nutritional status among adult women in urban India, 1998-2006. Asia Pac J Public Health 27, NP1241-NP1252.

10. Ramachandran N (2014) Persisting Undernutrition in India: Causes, Consequences and Possible Solutions. New Delhi: Springer India.

11. Black RE, Allen LH, Bhutta ZA et al. (2008) Maternal and child undernutrition: global and regional exposures and health consequences. Lancet 371, 243-260.

12. Subramanian SV \& Smith GD (2006) Patterns, distribution, and determinants of under- and overnutrition: a populationbased study of women in India. Am J Clin Nutr 84, 633-640.

13. Griffiths PL \& Bentley ME (2001) The nutrition transition is underway in India. J Nutr 131, 2692-2700.

14. Misra A, Singhal N, Sivakumar B et al. (2011) Nutrition transition in India: secular trends in dietary intake and their relationship to diet-related non-communicable diseases. J Diabetes 3, 278-292.

15. Green R, Milner J, Joy EJ et al. (2016) Dietary patterns in India: a systematic review. Br J Nutr 116, 142-187.

16. Singh A, Upadhyay AK \& Kumar K (2016) Birth size, stunting and recovery from stunting in Andhra Pradesh, India: evidence from the Young Lives Study. Matern Child Health J 21, 492-508.

17. Rai RK, Kumar S, Sekher M et al. (2015) A life-cycle approach to food and nutrition security in India. Public Health Nutr 18, 944-949.

18. Ghosh S, Barik A, Majumder S et al. (2015) Health \& Demographic Surveillance System Profile: the Birbhum population project (Birbhum HDSS). Int J Epidemiol $4 \mathbf{4}$, 98-107.

19. WHO Expert Consultation (2004) Appropriate body-mass index for Asian populations and its implications for policy and intervention strategies. Lancet 363, 157-163.

20. Basu S (2000) Dimensions of tribal health in India. Health Popul Perspect Issues 23, 61-70. 
21. Rutstein SO \& Johnson K (2004) The DHS Wealth Index. DHS Comparative Reports no. 6. Calverton, MD: ORC Macro.

22. Vyas S \& Kumaranayake L (2006) Constructing socioeconomic status indices: how to use principal components analysis. Health Policy Plan 21, 459-468.

23. Barik A, Rai RK \& Chowdhury A (2016) Alcohol use-related problems among a rural Indian population of West Bengal: an application of the Alcohol Use Disorders Identification Test (AUDIT). Alcohol Alcohol 51, 215-223.

24. Barik A, Rai RK, Gorain A et al. (2016) Socio-economic disparities in tobacco consumption in rural India: evidence from a health and demographic surveillance system. Perspect Public Health 136, 278-287.

25. Chatterjee S \& Hadi AS (2006) Regression Analysis by Example, 4th ed. New York: Wiley.

26. International Institute for Population Sciences (2016) National family Health Survey 2015-16, State Fact Sheet: West Bengal. Mumbai: IIPS.

27. Clarke P, O'Malley PM, Johnston LD et al. (2009) Social disparities in BMI trajectories across adulthood by gender, race/ethnicity and lifetime socio-economic position: 1986-2004. Int J Epidemiol 38, 499-509.

28. Brown PJ (1991) Culture and the evolution of obesity. Hum Nat 2, 31-57.

29. Glass TA \& McAtee MJ (2006) Behavioral science at the crossroads in public health: extending horizons, envisioning the future. Soc Sci Med 62, 1650-1671.

30. Pednekar MS, Gupta PC, Shukla HC et al. (2006) Association between tobacco use and body mass index in urban Indian population: implications for public health in India. BMC Public Health 6, 70.
31. Audrain-McGovern J \& Benowitz N (2011) Cigarette smoking, nicotine, and body weight. Clin Pharmacol Ther 90, 164-168.

32. Pednekar MS, Gupta PC, Hebert JR \& Hakama M (2008) Joint effects of tobacco use and body mass on all-cause of mortality in Mumbai, India: results from a population based cohort study. Am J Epidemiol 167, 330-340.

33. T VS, Ramadurg UY, Dorle AS et al. (2015) A cross-sectional study on pattern of alcohol consumption and body mass index among health institution students in Bagalkot. J Clin Diagn Res 9, LC06-LC09.

34. French MT, Norton EC, Fang H et al. (2010) Alcohol consumption and body weight. Health Econ 19, 814-832.

35. Little M, Humphries S, Patel K et al. (2016) Factors associated with BMI, underweight, overweight, and obesity among adults in a population of rural south India: a crosssectional study. BMC Obes $\mathbf{3}, 12$.

36. Sain R (1994) Nutritional status of tribal children in Birbhum district. Econ Polit Wkly 29, 1513.

37. Song M, Fung TT, Hu FB et al. (2016) Association of animal and plant protein intake with all-cause and cause-specific mortality. JAMA Intern Med 176, 1453-1463.

38. Viswanathan B, David G, Vepa S et al. (2015) Dietary Diversity and Women's BMI Among Farm Households in Rural India. LANSA Working Paper Series no. 3. Chennai: MS Swaminathan Research Foundation.

39. Varadharajan KS, Thomas T \& Kurpad AV (2013) Poverty and the state of nutrition in India. Asia Pac J Clin Nutr 22, 326-339.

40. Shetty PS (2002) Nutrition transition in India. Public Health Nutr 5, 175-182.

41. Khandelwal S \& Kurpad A (2014) Nurturing public health nutrition education in India. Eur J Clin Nutr 68, 539-540. 